\title{
Direct Determination of Ultratrace Arsenic in Blood Samples Using an in-situ Dielectric Barrier Discharge Trap Coupled With Atomic Fluorescence Spectrometry
}

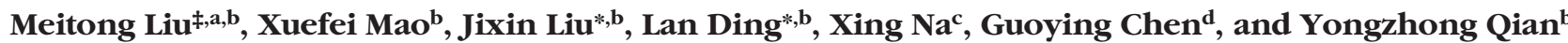 \\ ${ }^{a}$ College of Chemistry, Jilin University, Changchun 130012, P.R. China \\ ${ }^{b}$ Institute of Quality Standard and Testing Technology for Agro-products, \\ Chinese Academy of Agricultural Sciences, and Key Laboratory of Agro-food Safety and Quality, \\ Ministry of Agriculture and Rural Affairs, Beijing 100081, P.R. China \\ c Beijing Ability Technique Company, Limited, Beijing 100081, P.R. China \\ d Eastern Regional Research Center, Agricultural Research Service, \\ U.S. Department of Agriculture, Wyndmoor, PA 19038, USA
}

\begin{abstract}
A novel direct sampling hydride generation (HG) system was utilized and is first reported to introduce a blood sample into a in-situ dielectric barrier discharge atomic fluorescence spectrometer (DBD-AFS) for ultratrace determination of arsenic based on the gas phase enrichment (GPE) principle. The in-situ DBD unit was fitted with three concentric quartz tubes to replace the conventional atomizer in the AFS. Followed by a simple disruption for 2 minutes and centrifugation for 8 minutes of the blood sample in $3 \% \mathrm{HNO}_{3}$ (v:v) extractant, the arsenic extraction and protein precipitation can be achieved up to 40 multiple dilutions. A supernatant consisting of $5 \% \mathrm{HCl}(\mathrm{v}: \mathrm{v})$ and $5 \mathrm{~g} / \mathrm{L} \mathrm{KBH}_{4}$ in $1.5 \mathrm{~g} / \mathrm{L} \mathrm{KOH}$ was introduced into the HG-in-situ DBD-AFS. Then, arsenic generating from the HG was trapped
\end{abstract}

\section{INTRODUCTION}

Inorganic arsenic (As), including $\mathrm{As}(\mathrm{III})$ and $\mathrm{As}(\mathrm{V})$, found in the global environment and due to anthropogenic contamination is classified as one of the primary carcinogens $(1,2)$ affecting human health and can result in lung, liver, skin, cardiovascular and cerebrovas-

\footnotetext{
f= Author contributed equally (M. Liu)

*Corresponding authors:

E-mail: ljx2117@gmail.com (J.X. Liu)

E-mail:dinglan@jlu.edu.cn (L. Ding)

Tel: +86-10-82106563

Fax: +86-10-82106566
}

using $11 \mathrm{kV} \mathrm{DBD}$ at $110 \mathrm{~mL} / \mathrm{min}$ air, swept for 190 seconds at 500 $\mathrm{mL} / \mathrm{min} \mathrm{Ar}$, and released with $13 \mathrm{kV}$ at $180 \mathrm{~mL} / \mathrm{min}_{2}$. Under the optimal conditions, the linear regression coefficient $\left(\mathrm{R}^{2}\right)$ was 0.996 ranging from 0.05 to 300 $\mu \mathrm{g} / \mathrm{L}$. The method detection limit (LOD) obtained was $7 \mathrm{pg}$ arsenic, with a $3.9 \%$ precision using 11 repeated measurements for real blood samples. The spiked recoveries for the real blood samples were $96-107 \%$. Furthermore, it was found that the arsenic concentrations measured by the proposed method were not significantly different $(\mathrm{P}>0.05)$ from using microwave digestion in ICP-MS. The complete analysis, including sample pre-treatment, was performed within 15 minutes. The results show that the proposed method offers a fast and reliable analysis of ultratrace levels of arsenic in real blood samples.

cular diseases $(3,4)$. To prevent or cure arsenic poisoning, it is important to assess the arsenic levels in the human body for which a venous blood sample is always employed as a representative indicator. Hence, a fast, reliable, and accurate analytical method is indispensable for ultratrace arsenic detection. At present, instrumental approaches coupled with sample digestion pre-treatment are frequently employed during clinical diagnosis using inductively coupled plasma mass spectrometry (ICP-MS) (5-7), hydride generation atomic fluorescence spectrometry (HGAFS) (8-11), HG atomic absorption spectrometry (HG-AAS) (12-14), HG inductively coupled plasma optical emission spectrometry (HG-ICPOES) (15-17), anodic stripping voltammetry (ASV) (18), etc. However, the digestion process with these methods requires toxic reagents and causes possible contamination or loss of trace elements, and is time- and labor-intensive. Thus, direct sampling analysis without digestion by using acid extraction, slurry sampling (SLS), or electrothermal vaporization (ETV) is a fast method for clinical diagnosis, with the advantages of no elemental loss, high efficiency, and simple operation.

Acid extraction (19) is found to be a competent method for the analysis of blood samples and requires no instrumental adjustments of the atomic spectrometers. However, due to the complicated matrices of real blood samples, their protein, salts, and matrix interferences remain a puzzle and difficulty for a direct sample analysis method. While the foam caused in the hydride generator by protein interferes in the analytical process, arsenic extraction and protein precipitation can be achieved simultaneously by using an acid. In addition, the multifold dilution ability reduces the interferent concentration below the interference threshold of the analyte solution. Compared with the matrix modifier, matrix matching and other approaches, the acid extraction 
method is simpler and faster, and offers high analytical sensitivity and anti-interference in the atomic spectrometers. Among these instruments, ICP-MS offers highest sensitivity and a wide linear range (20-22). However, the cost and complex operation requirements become prohibitive for low throughput laboratories and hospitals. As an alternative, HG-AFS has been adopted as a powerful analytical tool for arsenic analysis in China due to the advantages of its high sample introduction efficiency, effective matrix separation, and low cost (23). Unfortunately, the detection limits (LODs) achieved with AFS are not sufficient for ultratrace arsenic analysis (ng/L or below levels).

The emergence of an efficient and low-cost gas phase enrichment (GPE) technique (24) remedies the low sensitivity of AFS. In comparison to the traditional GPE methods of graphite furnace, quartz tube and metal trap, the dielectric barrier discharge (DBD) consumes less energy, has no temperature gradient, a simpler structure for elemental pre-concentration, and is more suitable with AFS, AAS, OES, etc. DBD was first applied as an atomizer to AAS and then extended to AFS, as well as employed as an excitation source for OES and chemical vapor generation (CVG). In 2016, Liu et al. (25) first developed a novel tubular DBD for the pre-concentration of arsenic in HG-AFS, which achieved a stable and accurate As detection as low as $1 \mathrm{ng} / \mathrm{L}$ (20 $\mathrm{mL}$ sampling volume) in surface water as well as an 8-fold enrichment efficiency via $\mathrm{Ar}+\mathrm{O}_{2}$ trapping and $\mathrm{Ar}+\mathrm{H}_{2}$ release. Shortly thereafter, Kratzer et al. (2) confirmed that the arsenic was also trapped by a planar DBD atomizer coupled to HG-AAS resulting in a LOD of 0.16 $\mathrm{ng} / \mathrm{mL}$. Further analytical sensitivity was achieved with an in-situ DBDAFS based on a three-concentrictube DBD design. After introducing only $2 \mathrm{~mL}$ of sample solution, it achieved $2.8 \mathrm{pg}$ LOD and a 4-fold enhancement for absolute sensitivity. Meanwhile, the mechanism of arsenic pre-concentration by DBD is such that arsine from the $\mathrm{HG}$ is oxidized and trapped in $\mathrm{Ar}+\mathrm{O}_{2}$ discharge, and then released and atomized in $\mathrm{Ar}+\mathrm{H}_{2}$ discharge. Hence, the DBD pre-concentration technique can realize two targets for HG-AFS: enhancing instrumental sensitivity and eliminating interference. As a result, it enables the direct determination of ultratrace arsenic in blood samples using direct sample HGAFS without a digestion process.

In this study, a rapid analytical method for ultratrace arsenic in blood samples was developed using acid extraction/precipitation by HG-in-situ DBD-AFS, coupled with a modified gas liquid separator (GLS). After a simple acid protein precipitation of the blood samples by 40 multiple dilutions, a prepared solution was introduced into the direct sampling HG system, then the arsenic generated was trapped/ released by in-situ DBD. The proposed method can achieve an LOD of $7 \mathrm{pg}$ for a blood sample, with a $3.9 \%$ relative standard deviation (RSD), and the total analysis, including sample pre-treatment, can be performed within 15 minutes. It proved to be a simple, fast, lowcost, green, and safe method in comparison to the traditional AFS with digestion. Therefore, the proposed method is very suitable for the ultratrace arsenic determination in blood samples for fast clinical diagnosis and to protect human health.

\section{EXPERIMENTAL}

\section{Instrumentation}

A hydride generation atomic fluorescence spectrometer (AFS-9130, Beijing Titan Instrument Co. Ltd, Beijing, P.R. China) was used, equipped with an As hollow cathode lamp (HCL) (Beijing General
Research Institute for Non-Ferrous Metals, Beijing, P.R. China) as the light source. An in-situ DBD atomizer was used instead of the original atomizer of the instrument. The diagram of the HG-in-situ DBD-AFS system is shown in Figure 1-A. The HG apparatus was utilized as the direct sampling system. To introduce an extraction solution, a peristaltic pump (PP) and self-made gas-liquid separator were connected with a silicone tube. In comparison to the original GLS (i.d. $1.4 \mathrm{~cm} \times$ $10.5 \mathrm{~cm}, \sim 14 \mathrm{~mL}$ ) for AFS, the selfmade GLS (i.d. $2.3 \mathrm{~cm} \times 9.0 \mathrm{~cm}$, $\sim 37 \mathrm{~mL}$ ) is larger. For the original GLS, the sampling/gas inlet is in the middle of the GLS tube wall and waste discharging is performed in real time. While for the newly designed GLS, the gas inlet is placed at the bottom of the GLS tube to enhance the hydride generation reaction, and waste discharge is performed when the testing ends. The detailed parameters of the AFS instrument are listed in Table I. The $\mathrm{HCl}, \mathrm{KBH}_{4}$, and $\mathrm{KOH}$ concentrations were in accordance with a previous study (25) and were found to be sufficient for the hydride generation of arsenic in the acid extractant mentioned below.

TABLE I

Instrumental Conditions for HG-AFS

\begin{tabular}{ll}
\hline Parameters & Values \\
\hline $\begin{array}{l}\text { Lamp current } \\
\text { (total/main) }\end{array}$ & $80 / 40 \mathrm{~mA}$ \\
PMT voltage & $-270 \mathrm{~V}$ \\
HCL wavelength & $193.7 \mathrm{~nm}$ \\
Carrier gas & $500 \mathrm{~mL} / \mathrm{min}$ \\
Shield gas & $500 \mathrm{~mL} / \mathrm{min}$ \\
PP speed & $130 \mathrm{rpm}$ \\
$\mathrm{HCl}$ & $5 \%(\mathrm{v}: \mathrm{v})$ \\
$\mathrm{KBH}_{4}$ & $5 \mathrm{~g} / \mathrm{L}$ \\
$\mathrm{KOH}$ & $1.5 \mathrm{~g} / \mathrm{L}$ \\
\hline
\end{tabular}

The DBD unit is comprised of three concentric quartz tubes, coupled to a high frequency and high voltage power supply of $30 \mathrm{k} \mathrm{Hz}$ 
(Mev 40 kV, Xi'an MEV, Xi'an, P.R. China) (see diagram in Figure 1-B). The copper rod was inserted into the innermost part of the quartz tube and attached with ultraviolet glue as the high voltage electrode, and the copper wire, spirally wound on the outer side of the middle quartz tube, was used as the ground pole. It is the discharge chamber between the middle and innermost part of the quartz tubes where $\mathrm{Ar}, \mathrm{H}_{2}$, or air gases is introduced for discharge The outermost quartz tube was designed to pass the shielding gas, thereby preventing air from outside. The power supply was connected to the DBD electrodes to generate high voltage. The gas flow was precisely controlled by separate gas mass flow controllers (GMFC) (Beijing Seven Star Electronics, Beijing, P.R. China), and different gas channels for Ar, $\mathrm{Ar}+\mathrm{air}$, and $\mathrm{Ar}+\mathrm{H}_{2}$ were controlled by three-way valves, respectively.

Here, the Model X Series II ICPMS (Thermo Fisher Scientific, Bremen, Germany) was used to determine As in the blood samples after microwave digestion (Model TOPEX, PreeKem Scientific Instruments Co., Ltd., Shanghai, P.R. China) for the purpose of verifying the results of HG-in-situ DBD-AFS in this work. The detailed operating conditions of ICP-MS are listed in Table II. The instrumental LOD of arsenic was $0.025 \mu \mathrm{g} / \mathrm{L}$.

TABLE II

Instrumental Parameters of ICP-MS

\begin{tabular}{ll}
\hline Parameters & Values \\
\hline Incident RF power & $1150 \mathrm{~W}$ \\
Cooling Ar flow rate & $14 \mathrm{~L} / \mathrm{min}$ \\
Nebulizer Ar flow rate & $0.8 \mathrm{~L} / \mathrm{min}$ \\
Auxiliary Ar flow rate & $1.2 \mathrm{~L} / \mathrm{min}$ \\
Peristaltic pump & $50 \mathrm{rpm}$ \\
\hline
\end{tabular}

\section{Standard Solutions and Reagents}

All chemicals were of reagent grade and purchased from Sinopharm Chemical Reagent (Beijing, P.R. China) unless otherwise stated. Deionized water (18 $\mathrm{Mk} \Omega$ ) was prepared using a Milli-Q ${ }^{\circledR}$ integral purification system (Millipore Corporation, Billerica, MA, USA). Standard stock solution of arsenic (GBW(E)080117, $100 \mu \mathrm{g} / \mathrm{mL}$ ) was purchased from the National Research Center for Certified Reference Materials (NRCCRM) (Beijing, P.R. China), and diluted as required using 5\% $\mathrm{HCl}(\mathrm{v}: \mathrm{v})$. The argon carrier gas was $99.999 \%$ (v:v). $\mathrm{H}_{2}$ and air were produced by a hydrogen generator and air pump, respectively. $\mathrm{HNO}_{3}$ and $\mathrm{H}_{2} \mathrm{O}_{2}$ (Guarantee reagent, Beijing Chemical Reagents Co., Beijing, P.R. China) were used for digestion of the blood samples.

\section{Sample Preparation}

The venous blood samples were mixed in anticoagulant tubes, stored at $4{ }^{\circ} \mathrm{C}$ for transportation, and finally preserved under $-80{ }^{\circ} \mathrm{C}$ (for a week). An accurately weighed $0.25 \mathrm{~mL}$ of blood sample was added into $10 \mathrm{~mL}$ of $3 \% \mathrm{HNO}_{3}(\mathrm{v}: \mathrm{v})$ in a 50-mL centrifuge tube, and then mixed for 2 minutes using a high speed tissue disperser. After centrifuging at $5000 \mathrm{rpm}$ for 8 minutes for the protein precipitation, $2 \mathrm{~mL}$ of supernatant was introduced into the HG system for the next measurement.

For ICP-MS, a $0.5 \mathrm{~mL}$ of blood was placed into a digestion tank with $3 \mathrm{~mL} \mathrm{HNO}_{3}$ and $2 \mathrm{~mL} \mathrm{H}_{2} \mathrm{O}_{2}$, then pre-digested overnight. The following microwave digestion procedures were performed: (1) rinsing to $80{ }^{\circ} \mathrm{C}$ for 5 minutes; (2) heated to $120^{\circ} \mathrm{C}$ for 5 minutes; (3) then to $190{ }^{\circ} \mathrm{C}$ for 5 minutes and left standing for 20 minutes; (4) cooling to ambient temperature. The digestion solution was heated at $140{ }^{\circ} \mathrm{C}$ to remove the acid until it reached less than a $1-\mathrm{mL}$ residue.

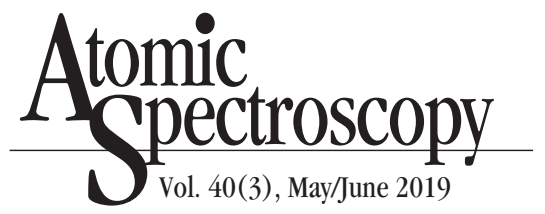

Finally, the sample solution was diluted to $10 \mathrm{~mL}$ with deionized water before measurement.

\section{Analytical Procedures of HG-in-situ DBD-AFS}

A schematic diagram of the analytical procedures for $\mathrm{HG}$-in-situ DBD-AFS is shown in Figure 1, and the steps were as follows. (A) A 2-mL prepared supernatant was introduced into the GLS by PP and mixed with $5 \mathrm{~g} / \mathrm{L} \mathrm{KBH}_{4}$ in 1.5 $\mathrm{g} / \mathrm{L} \mathrm{KOH}$. Ar carrier gas entered the GLS at $500 \mathrm{~mL} / \mathrm{min}$ and brought the arsenic hydride into the next DBD tube. (B) For trapping, $11 \mathrm{kV}$ discharge with $\mathrm{Ar}+\mathrm{O}_{2}$ was performed for DBD pre-concentration, and the arsenic oxides were trapped on the quartz tube surface. (C) After 190 seconds sweeping by Ar, $13 \mathrm{kV}$ discharge with $\mathrm{Ar}+\mathrm{H}_{2}$ was performed for release. Arsenic clusters were transferred into the AFS for measurement. (D) Arsenic was atomized in the AFS using $700 \mathrm{~mL} / \mathrm{min}$ of $\mathrm{Ar} / \mathrm{H}_{2}(\mathrm{v}: \mathrm{v}=5: 2)$ shield gas to support a diffusion flame

\section{Statistical Analysis}

The results of arsenic determination by HG-in-situ DBD-AFS and microwave digestion ICP-MS were statistically compared using the statistical software SAS 9.2. The statistical significance of differences between the two methods was assessed using the Student's $t$-test. A probability of 0.05 or lower ( $\mathrm{p}<0.05)$ was significant.

\section{RESULTS AND DISCUSSION}

\section{Gas-liquid Separator (GLS)}

GLS is an indispensable component of the HG system for AFS. In this work, the size of the inner part of the newly designed GLS ( 37 $\mathrm{mL}$ ) was larger than that of the original $(\sim 14 \mathrm{~mL})$, as mentioned above. It was expected that the larger inner chamber of the new GLS design would accommodate more foam as generated from the soluble 


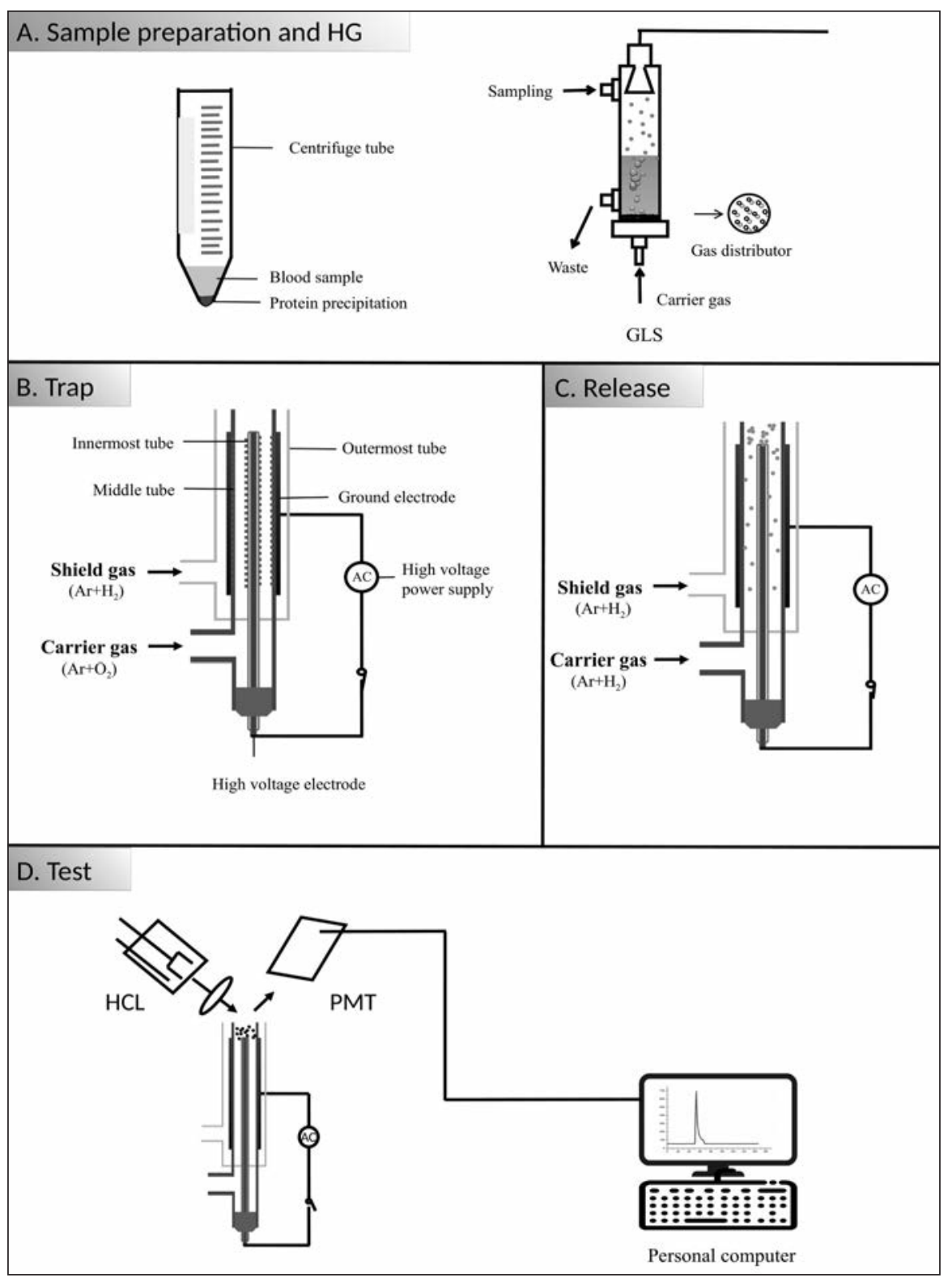

Fig. 1. Instrumental diagram and analytical process of HG-in-situ DBD-AFS. Panel $A$ is the procedure of acid extraction and direct sampling, as well as the structure of the direct sampling HG system. Panel B is the procedure of trapping arsenic by DBD, as well as the structure of DBD apparatus. Panel C is the procedure of releasing arsenic by DBD. Panel D is the procedure of arsenic measurement by AFS. W, waste liquid; GLS, gas-liquid separator; HCL, bollow cathode lamp; PMT, photomultiplier tube.

protein and, therefore, would cause no undesirable arsenic loss. To achieve a sufficient reaction of hydride generation via gas agitation, the carrier gas inlet was placed at the bottom of the GLS tube, and a gas distributor was employed to homogenize the carrier gas in the tube as well. In addition, to avoid analyte loss through the waste outlet, waste discharging was performed after one test ends. To confirm the difference between the two GLSs, $10 \mu \mathrm{g} / \mathrm{L}$ arsenic solutions were introduced into the original or new GLS and measured by HG-AFS and HG-in-situ DBD-AFS, respectively, and the results are shown in Figure 2. For HG-AFS (Figure 2A), the original GLS shows a sharp peak because of a high transfer speed for the analyte, while the new GLS demonstrates a lower and wider peak due to the large size of the inner chamber. For HG-in-situ DBDAFS (Figure 2B), the new GLS produces a higher and larger peak than the original one since there was no analyte loss caused in the discharging waste. It also proved that the DBD trap was able to pre-concentrate arsenic and release it in a short time to realize a sharp peak, which indicates a significant enhancement of analytical sensitivity. So, in spite of the larger size and lower transfer speed, the newly designed GLS is more suitable for the direct HG system resulting in favorable sensitivity without causing excessive foam.

\section{Acid Extraction and Protein Precipitation}

Blood samples are rich in protein which produces much foam during direct sampling analysis. The excessive foam can overflow from the GLS chamber into the atomizer or DBD trap, so that the atomization flame or DBD plasma extinguishes and some analytes become lost. Thus, it is necessary to remove the protein from the blood sample, which has no adverse influence on arsenic detection. At first, ethanol (blood: ethanol $=1: 2$ or $1: 10$, v:v) was used to precipitate the protein of the blood sample via centrifugation as described in the literature $(27,28)$. However, a large amount of foam remained in the supernatant during the $\mathrm{HG}$ reaction. Thus, this method proved to be unsuitable for a direct sampling analysis of the blood sample for HG.

$\mathrm{HNO}_{3}$ is another alternative method for precipitating protein 


\section{Atomic Spectroscopy \\ 1 Vol. 40(3), May/June 2019}
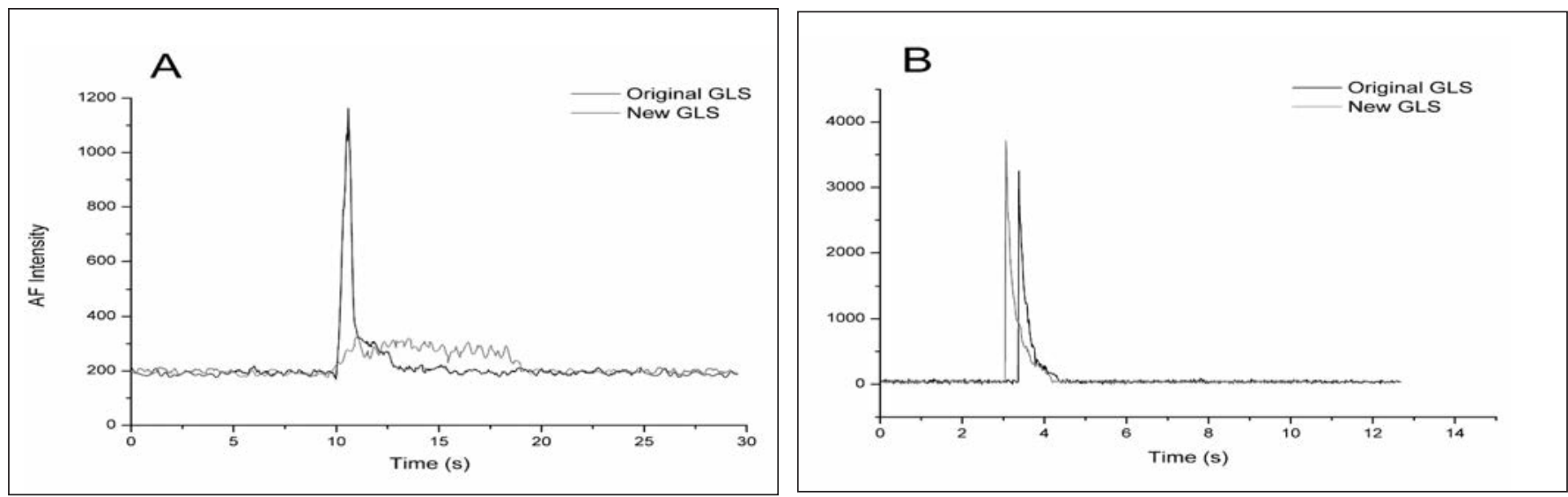

Fig. 2. Comparison of different GLS apparatuses using HG-AFS or HG-in-situ DBD-AFS. Panel A shows the results using HG-AFS, Panel B shows HG-in-situ DBD-AFS. In this work, 5\% $\mathrm{HCl}$ (v:v) and $5 \mathrm{~g} / \mathrm{L} \mathrm{KBH_{4 }}$ in $1.5 \mathrm{~g} / \mathrm{L} \mathrm{KOH}$ were used for both HG systems.

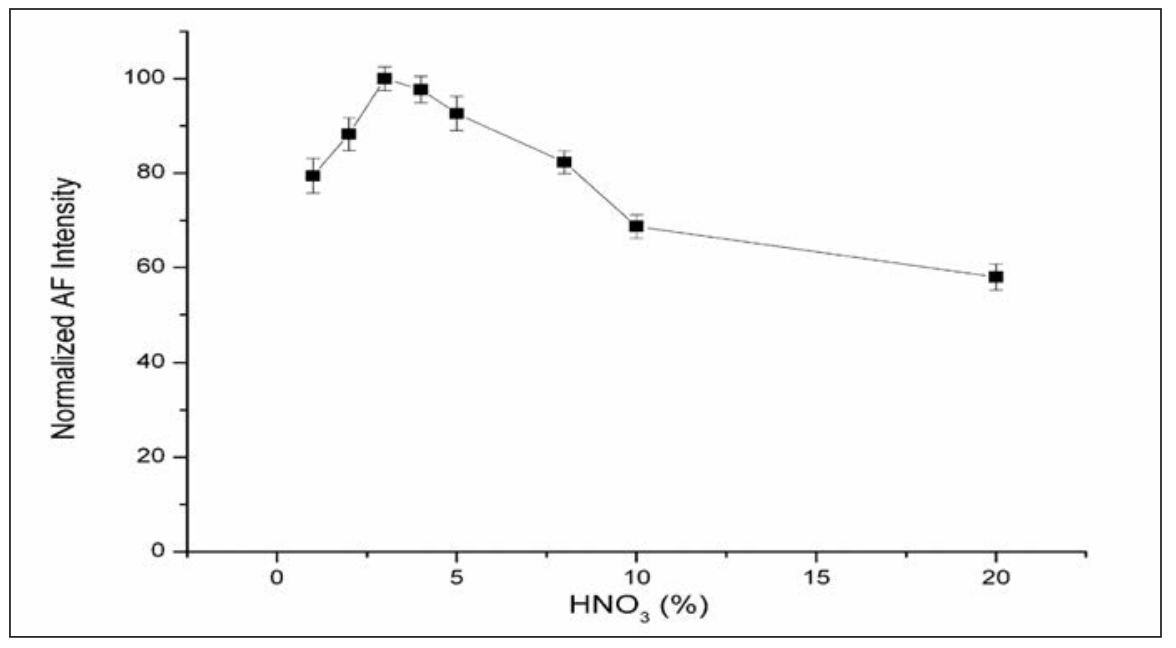

Fig. 3. Effect of different $\mathrm{HNO}_{3}$ concentrations on arsenic AF intensity by the HG-in-situ DBD-AFS. The AF intensity of $3 \% \mathrm{HNO}_{3}$ is set as 100, and the others are normalized.

(29) in an available acid medium to extract arsenic from the blood sample. To investigate the effects of different $\mathrm{HNO}_{3}$ concentrations on arsenic extraction and protein precipitation, $0.25 \mathrm{~mL}$ blood samples were mixed with $10 \mathrm{~mL} \mathrm{HNO}_{3}$, then mixed for 2 minutes using a high speed tissue disperser. Subsequently, the mixed solutions were centrifuged at $5000 \mathrm{rpm}$ for $8 \mathrm{~min}$ utes to achieve protein precipitation. Finally, a $2 \mathrm{~mL}$ amount of supernatant was introduced into the HG-in-situ DBD-AFS for measurement, and the results are shown in Figure 3. With an increase in $\mathrm{HNO}_{3}$ concentration, the arsenic AF inten- sity rose from $1 \%$ to $3 \%$ because more arsenic was extracted from the blood sample; when exceeding $3 \% \mathrm{HNO}_{3}$ concentration, the arsenic AF intensity declined considerably which might be due to the adverse influence on the generation efficiency of arsenic hydride caused by excessive $\mathrm{HNO}_{3}$. To verify the effect of $3 \% \mathrm{HNO}_{3}$ on hydride generation, $10 \mu \mathrm{g} / \mathrm{L}$ of As solutions was measured by HG-in-situ DBDAFS using 5\% $\mathrm{HCl}$ and 5\% $\mathrm{HCl}+3 \%$ $\mathrm{HNO}_{3}$ (v:v). The corresponding arsenic recoveries were $100 \%$ and $97 \%$, respectively. No adverse influence of $3 \% \mathrm{HNO}_{3}$ on arsenic hydride generation under a $\mathrm{HCl}$ medium was observed. On the other hand, to optimize the dilution ratio of $3 \%$ $\mathrm{HNO}_{3}, 0.25 \mathrm{~mL}$ of blood samples were pre-treated as mentioned above using different $\mathrm{HNO}_{3}$ volumes. As shown in Figure 4, a 40 times dilution demonstrated the highest arsenic AF intensity. However, 10 to 30 times dilutions led to weaker arsenic AF intensities, while excessive foam overflowed in the GLS chamber. By contrast, a 40 times dilution also reduces the arsenic AF intensity due to excessive dilution. After a 3\% $\mathrm{HNO}_{3}$ precipitation by 40 times dilution, no excessive foam overflowed from the GLS, except for a little foam generation due to the residual soluble protein in the sample supernatant. Meanwhile, the extraction efficiencies ranged from $96 \%$ to $107 \%$ (Table III) which indicates good stability. Therefore, 3\% $\mathrm{HNO}_{3}$ was chosen as the optimal acid extractant for arsenic extraction and protein precipitation.

\section{Trapping and Releasing Arsenic}

DBD is capable of providing energy for arsenic trapping and release due to the radicals, ultraviolet radiation, and active particles generated during discharge. Furthermore, the DBD energy depends on the use of the working gas and discharge voltage, regardless of DBD hardware. For direct 


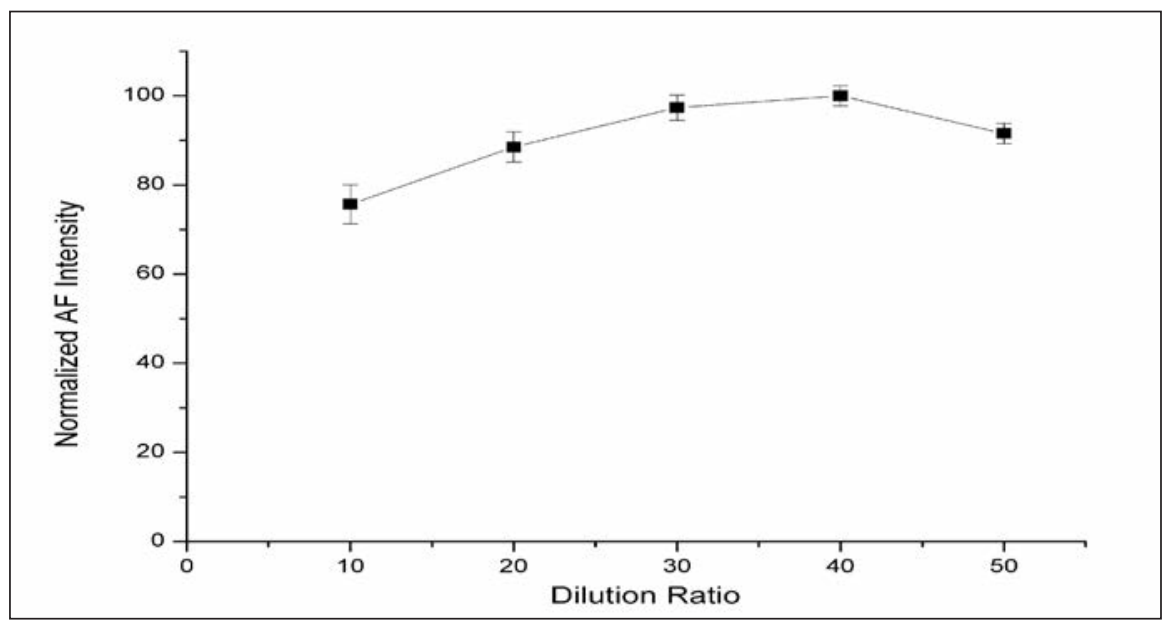

Fig. 4. Effect of the dilution ratios on arsenic detection in blood samples. The dilution ratios show $3 \%$ volumes of $\mathrm{HNO}_{3}$ solution to $0.25 \mathrm{~mL}$ blood sample (v:v). The arsenic AF intensity at 40 times dilution is set as 100, and others are normalized.

TABLE III

Extraction Efficiency, Spiked Recoveries and Measured As in Real Blood Samples $(\mathbf{n}=3)$

\begin{tabular}{|c|c|c|c|c|c|c|}
\hline Samples & $\begin{array}{l}\text { ICP-MS } \\
(\mu \mathrm{g} / \mathrm{kg})\end{array}$ & $\begin{array}{l}\text { Proposed } \\
(\mu \mathrm{g} / \mathrm{kg})\end{array}$ & $\begin{array}{c}\text { Extraction } \\
\text { Efficiency } \\
(\%)^{\mathrm{a}}\end{array}$ & $\begin{array}{l}\text { Added }^{b} \\
(\mu g / k g)\end{array}$ & $\begin{array}{l}\text { Found } \\
\text { ( } \mu \mathrm{g} / \mathrm{kg})\end{array}$ & $\begin{array}{c}\text { Recovery } \\
\text { (\%) }\end{array}$ \\
\hline Whole Blood 1 & $3.6 \pm 0.4$ & $3.5 \pm 0.5$ & 97 & 10 & $13.4 \pm 0.4$ & 97 \\
\hline Whole Blood 2 & $2.6 \pm 0.3$ & $2.7 \pm 0.2$ & 104 & 10 & $12.7 \pm 0.2$ & 100 \\
\hline Whole Blood 3 & $4.4 \pm 0.5$ & $4.4 \pm 0.4$ & 100 & 10 & $14.7 \pm 0.5$ & 107 \\
\hline Whole Blood 4 & $2.8 \pm 0.3$ & $2.7 \pm 0.1$ & 96 & 10 & $12.6 \pm 0.1$ & 96 \\
\hline Whole Blood 5 & $3.2 \pm 0.2$ & $3.3 \pm 0.2$ & 103 & 10 & $13.5 \pm 0.4$ & 106 \\
\hline
\end{tabular}

sampling of the blood supernatant, the discharge voltage and working gas flow rate should be re-considered because the $\mathrm{H}_{2}$ and water generation from the HG were changed. It has been proved that $\mathrm{O}_{2}$ in an $\mathrm{Ar}+$ air mixture is beneficial for the formation of arsenic oxides trapped on the quartz tube by DBD. To optimize air gas flow and discharge voltage, the prepared supernatants of the blood samples were introduced into the HG-in-situ DBD-AFS for measurement. Due to the fluorescence quench caused by $\mathrm{O}_{2}$, released As intensity by DBD rather than As breakthrough was employed.
As shown in Figure 5A, from 10 to $110 \mathrm{~mL} / \mathrm{min}$ the As intensity went up rapidly with an increase in air flow rate; after $110 \mathrm{~mL} / \mathrm{min}$, the As intensity demonstrates a plateau with favorable RSDs. In terms of discharge voltage (Figure 5B), the As intensity rose as the discharge voltage was increased to $11 \mathrm{kV}$, while it decreased subsequently after the highest intensity owing to unknown reasons during higher voltage discharge. Therefore, $11 \mathrm{kV}$ discharge at $110 \mathrm{~mL} / \mathrm{min}$ air flow rate was chosen as the optimal trapping condition.
On the other hand, excessive water vapor generating from the HG system can interfere in the DBD atomization, even extinguishes the plasma. Figure 6 shows that using more than $190 \mathrm{~s}$ for Ar sweeping can effectively eliminate water vapor interference. Thus, 190 seconds was chosen as the optimal sweeping time for DBD release.

In addition, trapping and release are both indispensable to arsenic pre-concentration, of which the release is the reverse process of DBD trapping. To obtain a favorable arsenic signal with a sharp peak, the trapping process has to be achieved as soon as possible. Thus, the effect of different $\mathrm{H}_{2}$ flow rates and discharge voltages on arsenic release was investigated, and the results are shown in Figure 7. As shown in Fig. $7 \mathrm{~A}$, prior to 180 $\mathrm{mL} / \mathrm{min}$, the As intensity rose with an increase of $\mathrm{H}_{2}$ flow rate; after $180 \mathrm{~mL} / \mathrm{min}$, the As intensity reached a plateau. For discharge voltage (Figure 7B), the As intensity showed an increase before $13 \mathrm{kV}$ and then a decline. As a result, $13 \mathrm{kV}$ discharge at $180 \mathrm{~mL} / \mathrm{min}_{2}$ flow rate was chosen as the optimal release condition.

\section{Analytical Performance}

Under the optimized conditions, the analytical performance of the HG-in-situ DBD-AFS system was evaluated. The method LOD (0.05 $\mathrm{mL}$ blood sample in $2 \mathrm{~mL}$ of dilution solution was introduced into the instrument) was $7 \mathrm{pg}(7 \mathrm{pg} /$ $0.05 \mathrm{~mL}=0.14 \mu \mathrm{g} / \mathrm{L}$ ) calculated by formula $3 \sigma / \mathrm{m}$ with 11 measurements in real extract samples close to the blank ( $\sigma$ is the standard deviation and $m$ is the slope of the calibration curve). In addition, the serial standard solutions from 0.05 to $300 \mu \mathrm{g} / \mathrm{L}$ were measured with a linear regression coefficient of $\mathrm{R}^{2}=0.996$. The RSD of 12 repeated measurements of real blood samples was $3.9 \%$, which proved to be good analytical precision. 


\section{Atomic Apectroscopy \\ 1 Vol. 40(3), May/June 2019}
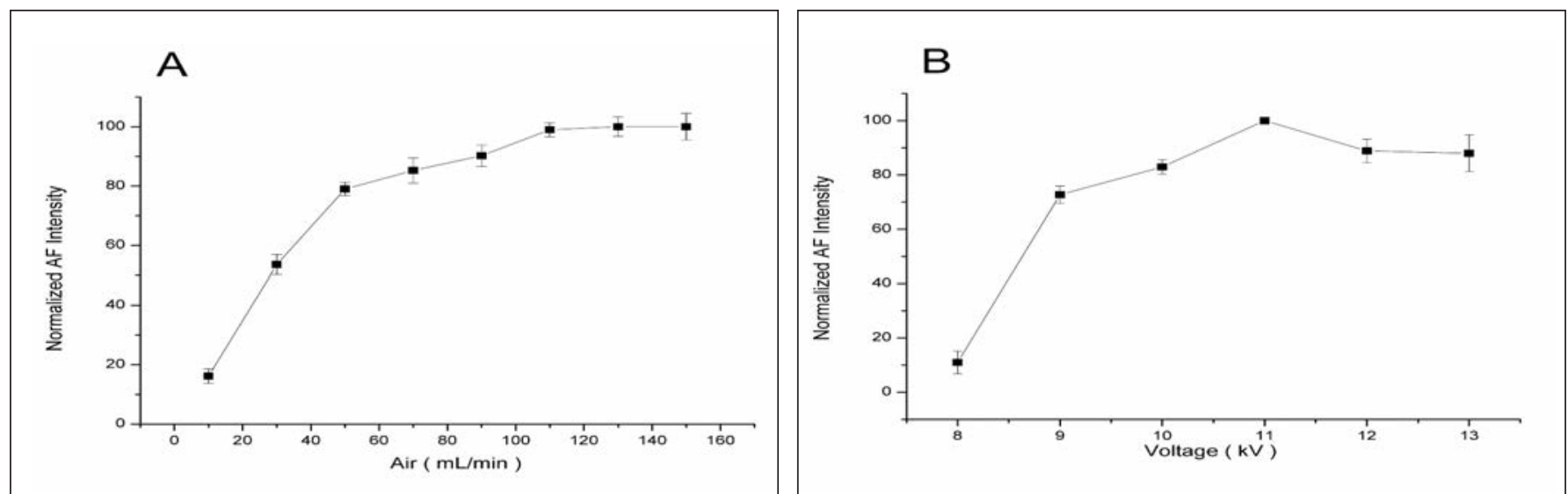

Fig. 5. Effect of air flow rate and discharge voltage on arsenic intensity for DBD trapping. Panel $A$ shows the As intensity under different air flow rates, of which $150 \mathrm{~mL} / \mathrm{min}$ is set as 100, and others are normalized to this value. Panel B shows the As intensity under different discharge voltages, of which $11 \mathrm{kV}$ is set as 100 , and the others are normalized to this value. A group of $10 \mu \mathrm{g} / \mathrm{L}$ As standards was used for measurement.

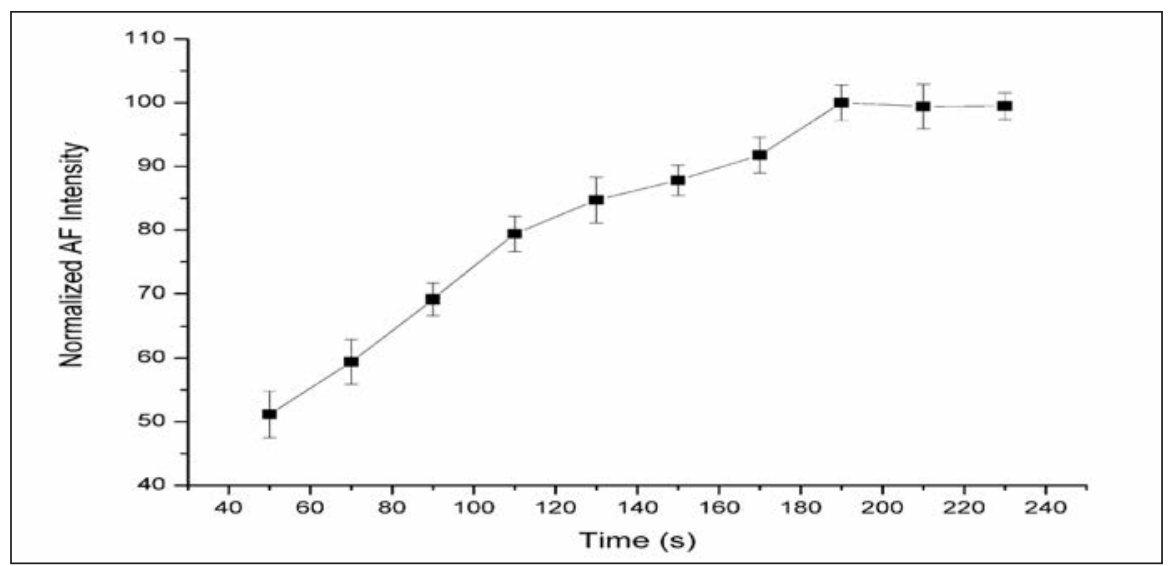

Fig. 6. Effect of sweeping time on eliminating the interference of water vapor from the hydride generator. For sweeping, $500 \mathrm{~mL} / \mathrm{min}$ of Ar carrier gas was employed. For trapping, $11 \mathrm{kV}$ discharge under $110 \mathrm{~mL} / \mathrm{min}$ air flow rate mixed with Ar carrier gas was performed; for releasing, $13 \mathrm{kV}$ discharge under $180 \mathrm{~mL} / \mathrm{min} \mathrm{H}_{2}$ flow rate mixed with Ar carrier gas. The As intensity of $190 \mathrm{~s}$ sweeping is set as 100, and the others are normalized to the value. A group of $10 \mu \mathrm{g} / \mathrm{L}$ As standards was used for measurement.

To investigate the effect of inorganic ion interference on the determination of arsenic by the proposed method, macro and micro elements ( $\mathrm{K}, \mathrm{Ca}, \mathrm{Na}, \mathrm{Mg}$ ), transition metals ( $\mathrm{Cu}, \mathrm{Zn}, \mathrm{Fe}, \mathrm{Co}, \mathrm{Ni})$, and hydride generation elements ( $\mathrm{Se}$, $\mathrm{Sb}, \mathrm{Bi}, \mathrm{Pb}, \mathrm{Hg}, \mathrm{Cd}$ ) were added to the real blood sample for arsenic determination. Compared with the blank sample of blood, the arsenic recoveries were $93-109 \%$, indicating no significant interference. Hence, the method proved to have suffi- cient capability of anti-interference for the proposed HG-in-situ DBDAFS.

\section{Real Sample Analysis}

To verify the established HG-insitu DBD-AFS approach, five real blood samples were analyzed for comparison with microwave digestion ICP-MS. As shown in Table III, the detailed results by the proposed method show no significant difference ( $p>0.05)$ with that of ICP-MS. The spiked recoveries were 96-
107\% which demonstrated good accuracy and stability for arsenic determination in blood samples.

\section{CONCLUSION}

In this study, a direct sampling HG system for the analysis of blood samples is reported for the first time employing the in-situ DBDAFS method based on the GPE principle. The LOD of $7 \mathrm{pg}$ arsenic can be obtained without requiring preconcentration in comparison to traditional HG-AFS. Including sample pre-treatment, the total analysis time is only 15 minutes. In addition, the proposed method offers high sensitivity, requires no sample digestion, and uses a rapid and simple operation for arsenic analysis in blood samples. The principles of the gas enrichment phase and dilution effect to analyze real samples are unique for the DBD technique. Due to the popularity of AFS in China, the proposed SLS-HG-in-situ DBD-AFS method has an excellent potential for its application in the detection of toxic elements to protect human health.

\section{ACKNOWLEDGMENT}

This work was financially supported by the National Natural Science Fund of China (No. 31571924), 

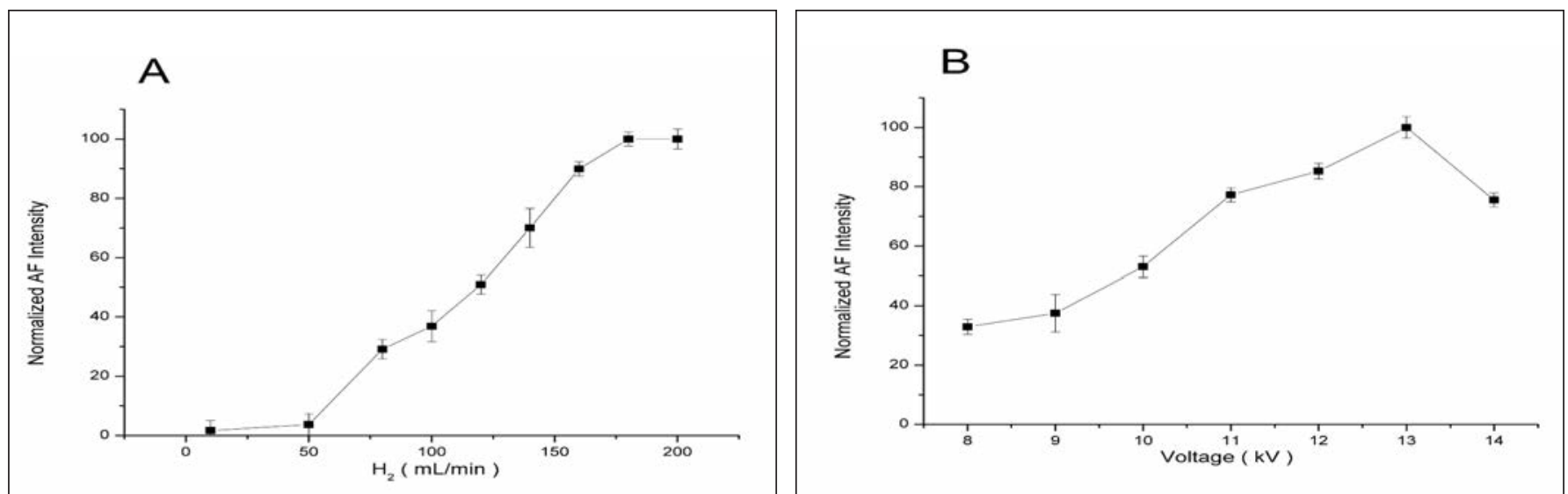

Fig. 7. Effect of $\mathrm{H}_{2}$ flow rates and discharge voltages on arsenic intensity for DBD release. Panel A shows the As intensity under different $\mathrm{H}_{2}$ flow rates, of which $180 \mathrm{~mL} / \mathrm{min}$ is set as 100, and others are normalized to this value. Panel B shows the As intensity under different discharge voltages, of which $13 \mathrm{kV}$ is set as 100, and the others are normalized to this value. A group of $10 \mu \mathrm{g} / \mathrm{L}$ As standards was used for measurement.

the National Key Research and Development Program of China (No. 2017YFD0801203), and the Central Public-interest Scientific Institution Basal Research Fund (No. Y2019XK05/1610072019001/ 1610072018003).

$\overline{\text { Received January 11, } 2019 .}$

\section{REFERENCES}

1. IARC Working Group on the Evaluation of Carcinogenic Risk to Humans. Arsenic, Metals, Fibres and Dusts. Lyon (FR): International Agency for Research on Cancer. (IARC Monographs on the Evaluation of Carcinogenic Risks to Humans, No. 100C.)

2. M. Calatayud, V. Devesa, and D. Vélez, Toxicol. Lett. 218(1), 70 (2013).

3. C. J. Chen, C. W. Chen, M. M. Wu, and T. L. Kuo, Br. J. Cancer 66, 888 (1992).

4. A. H. Smith, C. Hopenhayn-Rich, M. N. Bates, H. M. Goeden, I. Hertz-Picciotto, H. M. Duggan, R. Wood, M. J. Kosnett, and M. T. Smith, Environ. Health Perspect. 97, 259 (1992).

5. T. C. Gulsen, U. Zain, O. Mehmet, Y. Murat, A. Firat and D. M. Emin, At. Spectrosc. 39, 29 (2018).

6. T. R. Huang, and X. Wang. China
Condiment 40(8), 119 (2015).

7. X. G. Li, J. Lu, and Y. B. Huang. Phys. Test. Chem. Anal. 53(7), 792 (2017).

8. Z. Dong, M. Y. Gao, M. Y. Li, H. L. Zhang, Q. S. Zhang, and J. Cao, J. Food Saf. Qual. 7(3), 927 (2016).

9. Q. Yang, S. S. Zhang, N. Wu, Y. N. Hou, C. C. Xu, and Z. B. Xu, Rock Miner. Anal. 35(5), 481 (2016).

10. X. T. Cheng, F. F. Zhang, and J. Li, Chin. J. Endemiol. 36(11), 824 (2017).

11. Y. M. Cai, M. Li, L. J. Lu, and P. X. Zhang, Rock Miner Anal. 34(3), 325 (2015).

12. W. C. Nugraha, C. Elishian, and R. Ketrin, 1st International Symposium on Green Technology for Value Chains 60, (2017).

13. C. Machado, E. R. Pereira-Filho, and A. R. A. Nogueira, J. Braz. Chem. Soc. 27(7), 1273 (2016).

14. N. C. Maragou, G. Pavlidis, H. Karasali, and F. Hatjina, Anal. Lett. 50(11), 1831 (2017).

15. M. Welna and A. SzymczychaMadeja, Food Chem. 159, 414 (2014).

16. M. Welna, A. Szymczycha-Madeja, and P. Pohl, Anal. Lett. 47(12), 2104 (2014).

17. M. Savio, P. H. Pacheco, L. D. Martinez, P. Smichowski, and R. A. Dil, J. Anal. At. Spectrom. 25(8), 1343 (2010).
18. G. W. Kristoff; S. Pascal, V. D. B. Constant M. G., Anal. Chim. Acta 662(1), 1 (2010).

19. T. G. Kazi, H. I. Afridi, G. H. Kazi, M. K. Jamali, M. B. Arain, and N. Jalbani, Clin. Chim. Acta 369, 52 (2006)

20. K. L. Caldwell, J. Hartel, J. Jarrett, and R. L. Jones, At. Spectrosc. 26,1 (2005).

21. K. L. Linge, Geostand. Geoanal. Res. 32(4), 453 (2008).

22. J. M. Jarrett, R. L. Jones, K. L. Caldwell, and C. P. Verdon, At. Spectrosc. 28(4), 113 (2007).

23. J. Butcher, Appl. Spectrosc. Rev. 51(5), 20 (2016).

24. H. Wang, S. D. Zhang, Z. Y. Xu, J. Y. Lin, B. L. Huang, and W. Hang, J. Anal. At. Spectrom. 30, 852 (2015).

25. X. F. Mao, Y. H. Qi, J. W. Huang, J. X Liu, G. Y. Chen, X. Na, M. Wang, and Y. Z. Qian, Anal. Chem. 88, 4147 (2016)

26. P. Novák, J. Dedina, and J. Kratzer, Anal. Chem. 11 (88), 6064 (2016).

27. C. S. Olver, T. L. Webb, L J Long, H Scherman, and J E Prenni, Vet. Clin. Path. 39, 337 (2010).

28. E. J. Cohn, L. E. Strong, W. L. Hughes, D. J. Mulford, J. N. Ashworth, M. Melin, and H. L. Taylor. J. Am. Chem. Soc. 68, 459 (1946).

29. D. Y. Qin, and J. X. Liu, Mod. Sci. Instrum. 6, 86 (2006). 